\title{
Nearctic Achalcinae with a first Australachalcus species of North America (Diptera: Dolichopodidae)
}

\author{
MARC A.A. POLLET* \\ Research Group Terrestrial Ecology, Department Biology, Ghent University (UGent), K.L.Ledeganckstraat 35, B-9000 Ghent, \\ Belgium \\ and Department of Entomology, Royal Belgian Institute of Natural Sciences (KBIN), Vautierstraat 29, B-1000 Brussels, Belgium; \\ e-mail: mp@iwt.be
}

Key words. Diptera, Dolichopodidae, Achalcus, Australachalcus, Nearctic, North America, distribution

\begin{abstract}
Both sexes of Achalcus bicolor sp.n., Achalcus longicercus sp.n., and Australachalcus latipennis sp.n. are described as additions to the Nearctic achalcine fauna. Diagnoses of five unnamed Achalcus species represented only by females are given. A key to Nearctic males and females including 10 unnamed species is provided. The new Achalcus records considerably extend the known distribution of the genus in North America, especially in the central and eastern states. Australachalcus latipennis sp.n. is the first known Nearctic species of this predominantly Neotropical and New Zealand genus. Achalcus bicolor sp.n. from Montana, Manitoba and Ontario clearly belongs to the Achalcus flavicollis species group. The eastern Achalcus longicercus sp.n. is not included in the latter species group due to the lack of a dorsal bristle on tibia I and the absence of a preapical anterodorsal bristle on femur III in both sexes. It features postgonites with strong hook-like apical processes possibly unique to this species. The presence and number of dorsal bristles on tibia I seem to be of both diagnostic and phylogenetic relevance. All northern achalcine species were collected between June and September, whereas some Californian species were taken in May and Australachalcus latipennis sp.n. from Arizona in October - November.
\end{abstract}

\section{INTRODUCTION}

The first Achalcus species from North America, A. oregonensis and A. utahensis, were described by Harmston \& Miller (1966) in the genus Systenus. Later, Pollet \& Cumming (1998) published a revision of Nearctic Achalcus, adding another three species, A. californicus, $A$. dytei and $A$. similis together with notes on female specimens of six unnamed species. Apart from one female specimen from southern Ontario, and A. utahensis, all these specimens originated from near the pacific coast of Canada and the USA. Recently, in revising the Neotropical Achalcinae fauna, Pollet (2005) erected Australachalcus to include species with six dorsocentral bristles, epandrial setae inserted at the basis of the epandrial lobe, and usually showing a hypandrium with a ventrally spined apex and a surstylar midventral bristle with an apical enlargement.

Thanks to the collaboration of North American dolichopodid workers and by examining miscellaneous dolichopodids at the Canadian National Collection of Insects, the author discovered three additional achalcine species. In this paper, Achalcus bicolor sp.n., Achalcus longicercus sp.n., and Australachalcus latipennis sp.n. are described and an updated key to Nearctic species is provided. The former two species represent a considerable extension of the geographical range of Achalcus in the Nearctic, whereas A. latipennis is the first Australachalcus species recorded from North America. In addition, five unnamed Achalcus species known only from females are briefly described.

\section{MATERIAL AND METHODS}

The wing, antenna, coxa and femur I and the hypopygium of a paratype male of $A$. bicolor sp.n. and of the holotype specimen of A. latipennis sp.n. were mounted for drawing. To keep the holotype specimen of $A$. longicercus sp.n. as intact as possible, only its hypopygium was mounted which shows sufficient diagnostic features to enable an unequivocal identification of the species. Hypopygia of all three species were cleared in a $90 \%$ lactic acid solution for about 30 seconds in a microwave. Upon drawing, the above mentioned body parts were transferred into a polymere microtube and attached to the corresponding type specimen. Data on 31, 56 and 58 character states of the head, body (incl. thorax, abdomen, genitalia, and wing) and legs resp. were stored in the Microsoft Access ${ }^{\circledR}$ database ACHALCINAE which enabled quick comparison between these and previously described [Nearctic] achalcine species. On the basis of this database, the three species described here were incorporated in the key to males and females by Pollet \& Cumming (1998).

As in the previous Palaearctic and Nearctic Achalcus revisions (Pollet, 1996; Pollet \& Cumming, 1998), the following biometric ratios on the lengths of antennae and wings were measured in as many specimens as possible in order to provide additional diagnostic criteria: (i) body length; (ii) wing length; (iii) ratio of proximal versus apical section of vein $\mathrm{CuA}_{1}$; (iv) ratio of apical section of vein $\mathrm{CuA}_{1}$ versus outer crossvein (m-cu or tp), the so-called $\mathrm{CuA}_{\mathrm{x}}$ ratio (Bickel, 1994); (v) ratio (length) of first flagellomere versus scape and pedicel combined; (vi) ratio of arista versus first three joints of antenna. In addition, (vii) the ratio of the proximal versus the apical section of vein $\mathrm{M}_{1+2}$ was also calculated.

The ratios between the different segments of the legs were not included because of their low diagnostic value. Only the ratio between the first and second tarsomeres of leg III was calculated

\footnotetext{
* Address for correspondence: IWT-Vlaanderen, Bischoffsheimlaan 25, B-1000 Brussels, Belgium.
} 
since this is generally considered one of the generic features of Achalcus. In the descriptions of the individual species, "eye" refers to the vertical diameter of the eye, and the numbers of acrostichal (ac) and dorsocentral (dc) bristles reflect the number of ac and dc pairs. The scale used in Figs $1-11$ is mm.

Terms used for the male genitalia follow Cumming et al. (1995), as adopted for Achalcus by Pollet \& Cumming (1998). In describing the hypopygium, "dorsal" and "ventral" refer to the morphological position prior to genitalic rotation and flexion; as a result, the top of the drawing is actually the ventral face and the bottom the dorsal face. Special attention is given to the presence and shape of the hypandrium, phallus, epandrial lobe and setae, surstylus, ventral (VPE) and dorsal process (DPE) of the epandrium, postgonites and cercus.

Collection and preservation abbreviations: BMNH: The Natural History Museum, London, UK; CAS: California Academy of Sciences, San Francisco, California, USA; CNC: Canadian National Collection of Insects, Ottawa, Ontario, Canada; GMUG: Geologisches-Paläontologisches Museum, Universität Göttingen, Göttingen, Germany; LEMQ: Lyman Entomological Museum, McGill University, Ste. Anne de Bellevue, Quebec, Canada; MTEC: Montana State University, Bozeman, Montana, USA; MZLU: Zoological Museum, Lund University, Lund, Sweden; POLLET: private collection of the author; USNM: National Museum of Natural History, Washington D.C., USA; WSU: Maurice T. James Entomological Collection, Washington State University, Pullman, Washington, USA; ZMFK: Zoologische Forschungsinstitut und Museum "Alexander Koenig", Bonn, Germany; D: mounted on pin (dry); $\mathrm{W}$ : stored in $70 \%$ alcohol solution (wet).

Relevant geographical or habitat information on the collecting sites of the specimens added by the author but not indicated on the labels is given between square brackets.

Morphological abbreviations: ac: acrostichal, ad: anterodorsal, av: anteroventral; dc: dorsocentral, DPE: dorsal process of epandrium; MSSC: male secondary sexual character; pd: posterodorsal, pv: posteroventral; VPE: ventral process of epandrium; leg I, II, III: fore, middle and hind leg.

Sampling abbreviations: ET: emergence trap; MSW: "massive" sweep netting (with collected insect material transferred to a collecting jar with $70 \%$ alcohol prior to sorting); MT: Malaise trap; PT: pitfall trap; SW: "traditional" sweep netting (with extraction of individual specimens in the field with pooter, or vial filled with $70 \%$ alcohol). A distinction is made between MSW and SW as it has been observed that especially minute or very small species are sometimes overlooked during SW in contrast to MSW.

\section{KEY TO NEARCTIC ACHALCINAE}

\section{Males}

16 dc. Antenna with scape pubescent dorsally (Fig. 10). Arista very short, about $0.3 \times$ as long as first 3 antennal joints. All postocular bristles yellow. Wing broad, about $2 \times$ as long as wide. Tibia III with 2 ad and 2 pd bristles. Hypandrium with spined ventral apex................. Australachalcus latipennis sp.n. 5 dc. Scape bare. Arista at least as long as first 3 antennal joints. Uppermost $4-5$ postocular bristles brownish to black. Wing narrower, more than $2.5 \times$ as long as wide. Tibia III with 3 ad and 3 pd bristles. Hypandrium with smooth apex. .

2 Tibia I without dorsal bristles. Femur III without distinct ad preapical bristle. Entire mesonotum distinctly flattened on dorsum. Postgonites with distinct apical hook-like processes. Cercus large, elongate and tapering (Figs 5, 6). . . $\ldots \ldots \ldots \ldots \ldots$ Achalcus longicercus sp.n.
- Tibia I with 1 or 2 dorsal bristles. Femur III with distinct ad preapical bristle. Mesonotum with only flattened prescu-

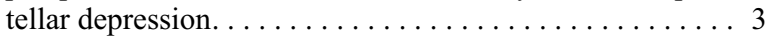

3 Tibia I with 1 dorsal bristle at basal $1 / 4 \ldots \ldots \ldots \ldots \ldots 4$

Tibia I with 2 dorsal bristles. . . . . . . . . . . . . . . 6

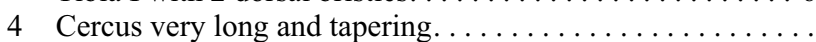
......... Achalcus utahensis (Harmston \& Miller, 1966)

Cercus of moderate size, elongate triangular. ........5

5 Thorax, including pleura, mainly brown. Scape and pedicel infuscated dorsally. Halter slightly infuscated. Epandrial lobe with one single flattened apical bristle............ ........ Achalcus oregonensis (Harmston \& Miller, 1966)
Thorax, including pleura, mainly reddish yellow, with brownish tinge. Scape and pedicel entirely yellow. Halter pale. Epandrial lobe with 2 flattened apical bristles....... . ........ Achalcus californicus Pollet \& Cumming, 1998

6 Thorax, including pleura and propleura, yellowish brown to brown. Antenna dark with only pedicel largely yellow. Palp greyish brown. Halter dark. Hypopygium small with pale postgonites. . . . A Achalcus similis Pollet \& Cumming, 1998 - Thorax reddish yellow with pleura slightly infuscated. Antenna mainly yellow. Postgonites dark. . . . . . . . . 7

7 Abdominal tergites black, sternites mainly dark brown. Antenna with $1^{\text {st }}$ flagellomere dark on less than dorsal half, with acute apex. . . Achalcus dytei Pollet \& Cumming, 1998 - Abdominal tergites brown, sternites yellowish white. Antenna with $1^{\text {st }}$ flagellomere rather uniformously brownish yellow, with rather blunt apex...... Achalcus bicolor sp.n.

\section{Females}

Pollet \& Cumming (1998) listed short diagnoses of females of six unnamed Achalcus species, indicated as Achalcus sp. 'N1' to 'N6'. Achalcus sp. 'N3' is considered here conspecific with $A$. bicolor sp.n. (see further). In the present study, another six female specimens are characterized as belonging to five additional unnamed species, listed as Achalcus sp. 'NA07' to 'NA11'. Codes used by Pollet \& Cumming (1998) are slightly modified here (e.g. 'N1' is replaced by 'NA01', in order to separate Nearctic from unnamed Neotropical females, indicated as 'NTx'). In the following key, both described and unnamed species are incorporated to allow provisional identification of newly collected specimens. Species are listed together in the same couplet, when they could only be separated by minor differences (mainly in coloration) but, nevertheless, do not seem to be conspecific.

16 dc. Scape with dorsal pubescence. All postocular bristles yellow. About 8-10 small setae between first three dc, presutural and sutural bristle. Tibia III with 2 ad and 2 pd bristles. ............... Australachalcus latipennis sp.n. - 5 dc. Scape bare. Uppermost 4-5 postocular bristles brownish to black. No additional setae present. Tibia III with 3 ad and 3 pd bristles................. 2

2 Tibia I without dorsal bristles. Femur III with one indistinct, yellow ad preapical bristle. Entire mesonotum distinctly flattened on dorsum. ......... Achalcus longicercus sp.n.

- Tibia I with 1 or 2 dorsal bristles. Femur III with one distinct, dark ad preapical bristle. Mesonotum with only flattened prescutellar depression. . . . . . . . . . . . 3

3 Tibia I with 2 dorsal bristles. . . . . . . . . . . . . . . 4

- Tibia I with 1 dorsal bristle. . . . . . . . . . . . 10

4 Thorax blackish brown........... Achalcus sp. 'NA02'

- Thorax reddish yellow, at most with dark anterior lateral spots and dark prescutellar depression, or yellowish brown

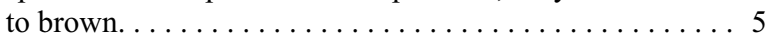

5 Thorax entirely pale reddish yellow. . . . . . . . . 6

- Thorax at least partly infuscated, or uniformously yellowish brown to brown. . . . . . . . . . . . . . . . 8 
6 Abdominal tergites dark brown. Sternites whitish to pale brown, with $5^{\text {th }}$ and $6^{\text {th }}$ sternite darker. . . . . . . . . . . Abdominal tergites yellowish white to brown. Sternites yel-

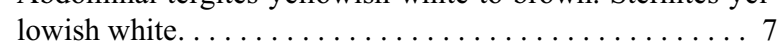

7 Tibia III with 2 ad bristles......... Achalcus sp. 'NA11'

- Tibia III with 3 ad bristles. ... Achalcus bicolor Pollet sp.n.

8 Thorax yellowish brown to brown. Palp dark. Tarsomeres pseudo-annulated..... Achalcus similis Pollet \& Cumming - Thorax reddish yellow with dark anterior lateral spots and dark prescutellar depression. . . . . . . . . . . . . . 9

9 Palp entirely pale yellow.......... Achalcus sp. 'NA07'

- Palp whitish yellow with large dark brown spot on apical $1 / 2$. ........................ Achalcus sp. 'NA10'

10 Thorax dark brown. Sternites dark brown. Femur I and III with one row of distinct av bristles. ........... Achalcus sp. 'NA05', Achalcus sp. 'NA08'

- Thorax dark brown, with some parts distinctly paler. Sternites at least partly whitish. Femur I and III without distinct av row of bristles. ..... Achalcus sp. 'NA01', Achalcus sp. 'NA04', Achalcus sp. 'NA06', Achalcus sp. 'NA09'

\section{GENUS ACHALCUS LOEW, 1857}

Type species: Porphyrops flavicollis Meigen, 1824 Achalcus flavicollis (Meigen, 1824) designated by Robinson (1970: 22)

Two Neotropical (A. bilineatus Pollet, 2005; A. tibialis Pollet, 2005), all eight Palaearctic and certainly six named Nearctic Achalcus species (A. bicolor sp.n., A. californicus, A. dytei, A. oregonensis, A. similis, A. utahensis) belong to the following species group:

\section{Achalcus flavicollis species group Pollet (2005)}

Diagnosis. Middle-sized, elegant species; at least thorax largely pale; $1^{\text {st }}$ flagellomere triangular, acute; male: femur I with strong basoventral bristle, without other erect av bristles; aedeagus with slight subapical bend. The basoventral bristle on femur I is present in all species, but the subapical dorsal bend of the aedeagus was found in only half of the European and 4 of the 5 Nearctic species. Although some species of the Achalcus costaricensis species group feature a reddish yellow thorax as well, they always lack the basoventral bristle of femur $I$ and the $1^{\text {st }}$ flagellomere has a subcircular to rounded triangular shape (Pollet, 2005).

Description (exceptions or extremes are given between brackets). Rather stout to slender, small to rather small species with wing length between $1.8 \mathrm{~mm}$ (A. nigropunctatus Pollet \& Brunhes, 1996) and $3.1 \mathrm{~mm}$ (A. tibialis). Face as wide to $2.5 \times$ as wide as frontal ocellus $(0.5 \times$ as wide in $A$. tibialis). Clypeus usually bare, in 5 species with short dense white pubescence. Frons and occiput brown to dark brown, frons usually strongly dusted. Palp rather large to large, between $1 / 3$ and $3 / 5$ of eye, usually ovoid, more rarely elongate truncate or with truncated (square) apex. Upper postoculars usually dark, lower pale [all postoculars pale in A. cinereus (Haliday in Walker, 1851), A. nigropunctatus and A. tibialis]. Antenna with bare scape, and pedicel laterally compressed and with apical crown of bristles; first flagellomere from ovoid triangular to distinctly acute and tapering, longer than scape and pedicel combined (of equal length in Neotropical spe- cies). Arista apical to subapical, always inserted on outer face of first flagellomere, with microscopic pubescence. Body unmetallic, with thorax laterally compressed, mostly reddish yellow (11 of 16 species), more rarely yellowish brown or dark brown. Postnotum usually with black frontolateral triangle. 4-7 ac, biserial, usually reaching $4^{\text {th }} \mathrm{dc}$, as long to $2 \times$ as long as distance between rows. 5 dc. One large, 1 small and 1 minute humeral bristle, 1 internal posthumeral, 1 presutural, 2 notopleural, 2 supraalar and 1 postalar bristles. Minute sutural bristle present in 11 species. Upper propleura bare or with 1 minute seta, lower propleura with 2-7 minute setae and 1 strong prothoracic bristle. Additional bristles between first $3 \mathrm{dc}$, presutural and sutural bristles absent. Veins $\mathrm{M}_{1+2}$ and $\mathrm{R}_{4+5}$ slightly to distinctly diverging, especially in basal $2 / 3$, sometimes nearly parallel near apex. Proximal section of $\mathrm{CuA}_{1}$ 1.7-2.9 $\times$ as long as apical section. $\mathrm{CuA}_{\mathrm{x}}$ ratio 1.4-2.3. Abdominal tergites brown to dark brown in 14 species; $1^{\text {st }}$ to $5^{\text {th }}$ tergite pubescent. Sternites whitish yellow to yellow in 12 species; $5^{\text {th }}$ sternite with strong caudal invagination to enclose ventral part (hypandrium, phallus, epandrial lobes) of hypopygium. Hypandrium simple, rather stout and straight. Phallus slender, either straight or with subapical dorsal bend. Epandrial lobe slender with 3 small bristles on apical $1 / 2$ of shaft, and 1 blunt apical bristle ( 2 apical bristles in A. californicus). Surstylus rather robust, widest at apex, with large, simple midventral bristle (latter with small apical flag in $A$. tibialis). Cercus usually rather small, elongate triangular or rounded rectangular (large, strongly elongate and tapering in A. flavicollis, A. thalhammeri Lichtwardt 1913, A. tibialis and A. utahensis). VPE, DPE and postgonites distinct, latter often conspicuously dark. Legs whitish to reddish yellow, often with $5^{\text {th }}$ tarsomeres dark brown. Coxa II usually with dark brown outer spot. Coxa III with 1 erect bristle at about middle. Femur I always with 1 erect basoventral bristle at basal $1 /{ }_{4}$ to $1 / 6,0.6-1.6 \times$ as long as femur is deep; latter bristle sometimes basad of row of small, inclined av bristles. Femur II with 1 row of small av bristles along entire length in Nearctic species, and with 1 row of small to strong pv bristles in all species. Femur II and III with 1 distinct preapical ad bristle (latter bristle on femur III absent in male $A$. vaillanti Brunhes, 1987). Femur III with distinct basodorsal bristles on basal $1 / 4$ to $2 / 5$. Tibia I usually with 1 dorsal bristle at basal $1 / 4$ to $1 / 3$ ( 2 bristles in A. bicolor, A. dytei and A. similis). Tibia II with 2 ad, 2 pd and 3 apical bristles; usually without ventral bristles (male $A$. vaillanti and $A$. tibialis with specific ventral chaetotaxy). Tibia III usually with $3 \mathrm{ad}, 3 \mathrm{pd}$ and 3 large apical bristles ( 2 ad in A. nigropunctatus, and 2 apical bristles in $A$. bilineatus); with pd row of erect setae on apical $1 / 3$ to $2 / 5$, and with 3-9 minute erect setae amid dense ventral pubescence. First tarsomere of leg III $0.7-0.9 \times$ as long as $2^{\text {nd }}$ tarsomere.

\section{Achalcus bicolor sp.n. (Figs 1-4)}

Diagnosis. Small, rather stout species with pale reddish yellow thorax. Scape and pedicel of antenna pale yellow, first flagellomere rather uniformously brownish yellow, triangular, with rather blunt apex. Abdominal tergites 

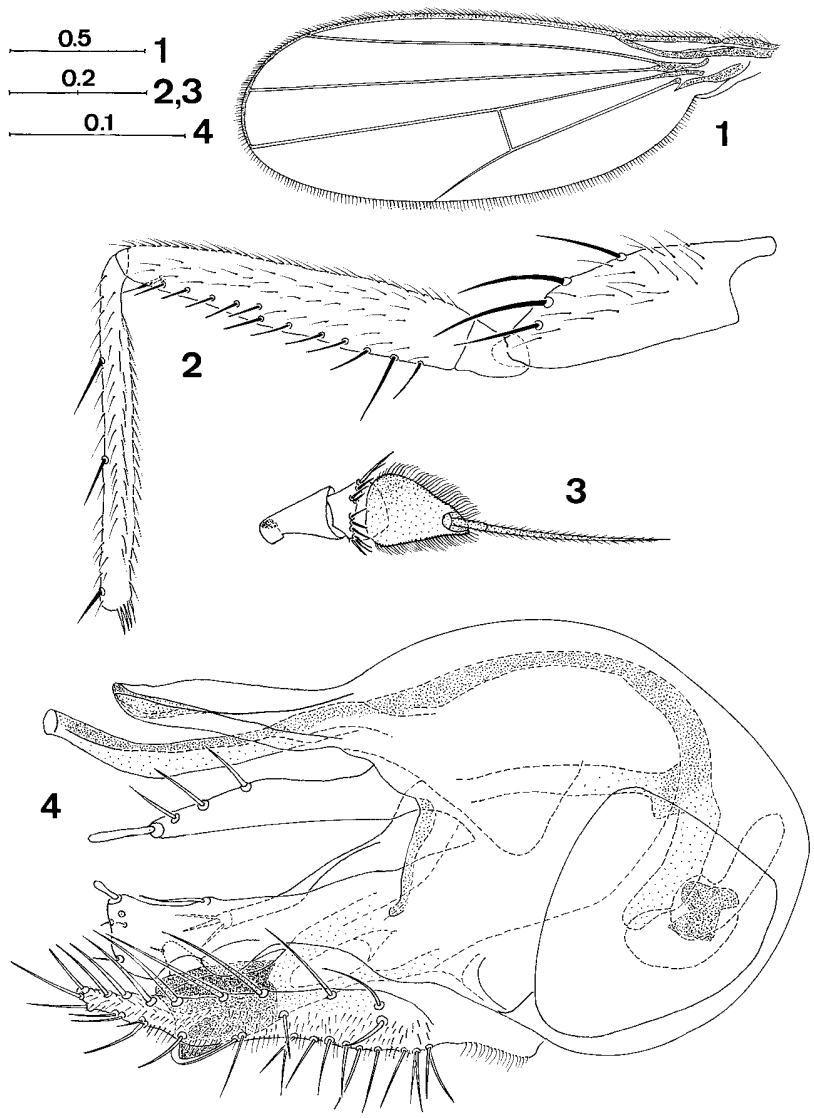

Figs 1-4. Achalcus bicolor sp.n. (male paratype): 1 -wing; 2 - coxa, femur and tibia I; 3 - antenna; 4 - hypopygium.

brown, sternites yellowish white. Femur I with basoventral bristle (MSSC), basad of row of inclined av bristles. Tibia I with 2 dorsal bristles. Hypopygium small with all appendages pale yellow except for phallus and dark postgonites; cercus elongate triangular.

Description. Male. Rather stout species. Body length 1.6-2.3 mm; wing length 1.9-2.0 $\mathrm{mm}(\mathrm{n}=4)$.

Head. Face yellowish brown, dusted, broad, about $2 \times$ as wide as frontal ocellus. Uppermost 4 postocular bristles brownish, lower 7 pale yellow. Palp ovoid, large, more than $1 / 3$ of eye, yellowish white. Antenna (Fig. 3) with scape and pedicel yellow; first flagellomere brownish yellow, especially on dorsal border, triangular, $1.4 \times$ as long as deep and $1.3 \times$ as long as scape and pedicel combined. Arista $1.4 \times$ as long as first three antennal joints, apical.

Thorax. Mesonotum, including pleura and scutellum, pale reddish yellow with notopleuron, posterior rim of scutellum and postnotum very slightly infuscated. 4 ac, $2 \times$ as long as distance between rows. One minute sutural bristle present. Abdomen with tergites mainly brown with $1^{\text {st }}$ tergite brownish yellow. Sternites yellowish white, with dark pubescence. Genital capsule brown, somewhat yellowish anterodorsally. Hypopygium (Fig. 4) with simple, straight hypandrium; phallus dark, with distinct subapical bend; surstylus with simple midventral bristle; VPE and DPE evident; postgonites dark brown; cercus moderate-sized, elongate triangular, outreaching surstylus.

Wing (Fig. 1). Halter pale, shaft infuscated. Wing pale with yellow veins; veins $\mathrm{R}_{4+5}$ and $\mathrm{M}_{1+2}$ distinctly diverging. Proximal section of vein $\mathrm{M}_{1+2} 0.9 \times$ as long as apical section; proximal section of vein $\mathrm{CuA}_{1} 2.4 \times$ as long as apical section; $\mathrm{CuA}_{\mathrm{x}}$ ratio 2.0.

Legs including coxae and trochanters whitish yellow, only coxa II with dark spot. Femur I (Fig. 2) with 1 erect ventral bristle inserted at about basal $1 / 5$; bristle $0.9 \times$ as long as femur is deep (MSSC), basad of row of small inclined av bristles, less than $1 / 2$ as long as femur is deep; with 1-2 pv preapical bristles. Femur II with 1 strong ad and 1 strong pv preapical bristles; with av and pv row of small inclined bristles, at basis about $1 / 2$ as long as femur is deep; pv row producing 1 strong pv preapical bristle. Femur III with 1 strong ad and 1 strong av preapical bristles. Tibia I slightly darker than femur, with 2 dorsal bristles at less than basal $1 / 3$ and at about basal $2 / 5$. Tibia II with 2 very strong ad bristles at basal $1 / 4$ and $1 / 2$, and 1 strong pd bristle. Tibia III with 3 rather strong ad and 3 rather strong pd bristles, and 5 minute erect ventral setae amid dense pubescence. Tarsus I concolorous with tibia I, tarsus II and III whitish yellow. First tarsomere of leg III $0.8 \times$ as long as $2^{\text {nd }}$ tarsomere.

Female. Body length 2.3-2.6 mm; wing length 2.0-2.2 $\mathrm{mm}(\mathrm{n}=6)$. As in male, except for the following: face broad, more than $2 \times$ as wide as frontal ocellus. Antenna mainly pale with scape and pedicel yellow; $1^{\text {st }}$ flagellomere brownish, raddish-shaped, as long as deep and $1.1 \times$ as long as scape and pedicel combined. Arista $1.8 \times$ as long as first three antennal joints, apical. Proximal section of $\mathrm{CuA}_{1} 2.1 \times$ as long as apical section; $\mathrm{CuA}_{\mathrm{x}}$ ratio 1.9. Abdominal tergites brown with 1 st tergite brownish yellow; 8th abdominal segment yellowish white, with 8 dark brown dornen and pale, broad-based cerci. Hind tibia with 4-6 minute ercet setae amid dense pubescence.

Type material. Holotype, ô, CANADA, Manitoba, Assiniboine - Souris River Fork [1 km E of Treesbank, fairly open shallow rocky banks lined with willow and alder trees], 11.viii.1993 (CNC; W). Paratypes, same site as holotype, $10^{0}$ 3 , 4.viii.1993; 2 ㅇ, 19.viii.1993; 1 ㅇ, 2.ix.1993 (all CNC; W); Ontario, Guelph, University arboretum (vegetation bordering brook), 19, 18.viii.1994, SW, M. Pollet (POLLET; W) (specimen sp. "N3" in Pollet \& Cumming, 1998); USA, Montana, Madison Co., Red Bluff, $2.5 \mathrm{~km}$ ENE of Ennis [pasture],

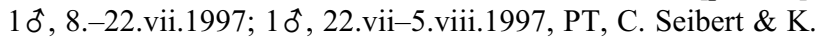
O'Neil (all MTEC; D).

Etymology. The name "bicolor" refers to the distinct difference in colour between thorax and abdominal tergites in this species.

Remarks. A comparison of the Guelph specimen listed as Achalcus sp. "N3" in Pollet \& Cumming (1998) with female specimens of $A$. bicolor from Manitoba did not reveal any differences and it is thus to be made a paratype. The two male specimens from Montana seem callows as they are considerably paler than the holotype male, especially the tergites. 


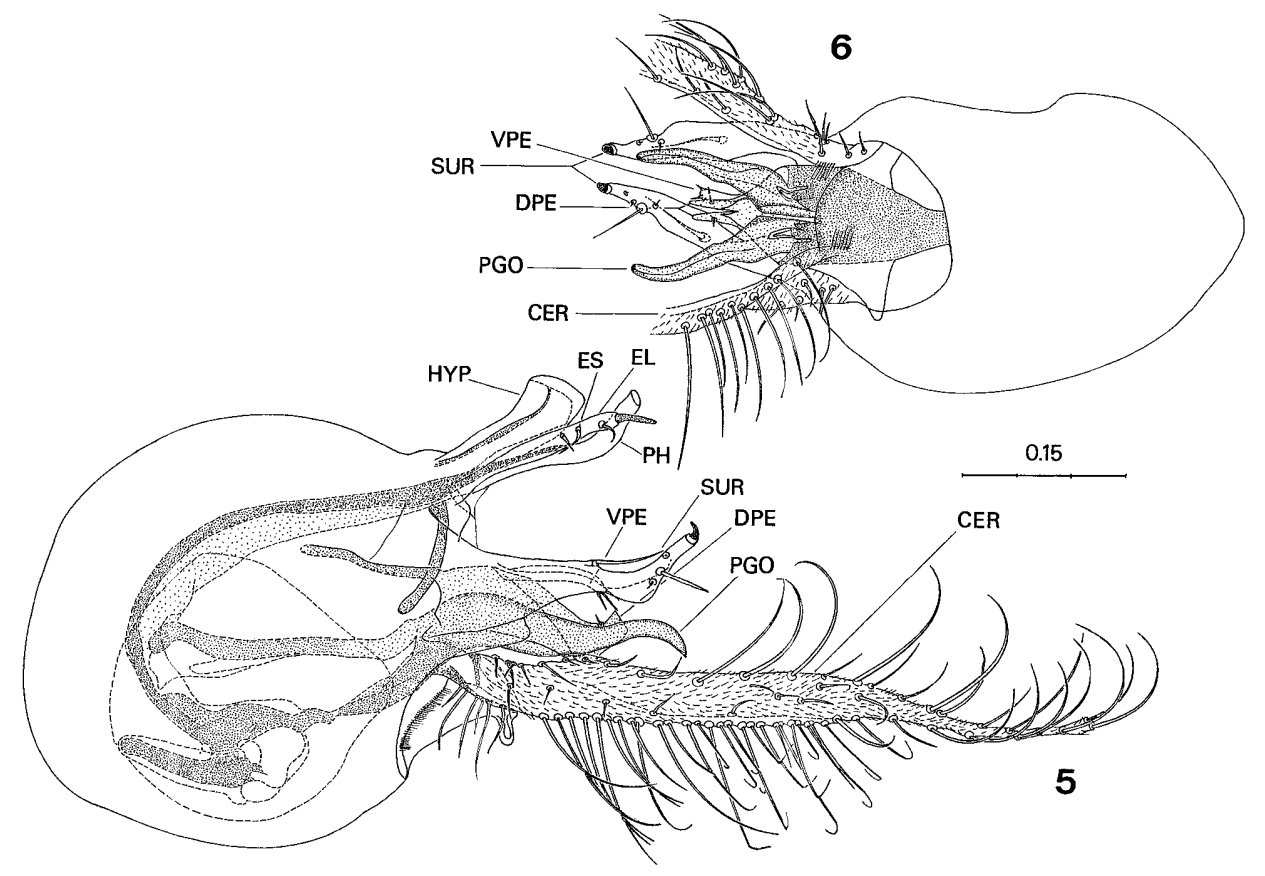

Figs 5-6. Achalcus longicercus sp.n. (holotype). Hypopygium. 5 - lateral view; 6 - dorsal view with cerci only partly shown and epandrial lobes, phallus and hypandrium omitted. Abbreviations: cer, cercus; el, epandrial lobe; es, epandrial setae; hyp, hypandrium; ph, phallus; pgo, postgonites; sur, surstylus.

\section{Achalcus longicercus sp.n. (Figs 5-6)}

Diagnosis. Small, rather slender species with pale reddish yellow thorax. Male with inner frontal ommatidia of eye brilliantly greenish blue (MSSC). Scape and pedicel of antenna mainly yellow, infuscated dorsally; first flagellomere pale brown, triangular, with rather acute apex. Abdominal tergites pale brown, sternites whitish yellow. Femur I with basoventral bristle (MSSC), basad of row of inclined av bristles. Femur II and III with ventral row of robust, erect pv bristles. Femur III without ad preapical bristle. Tibia I slightly thickened, without dorsal bristles. Genital capsule large and globular. Hypopygium with large, elongate and tapering cercus, and postgonites showing apical hook-like processes.

Description. Male. Rather slender species. Body length $2.4 \mathrm{~mm}$; wing length $2.3 \mathrm{~mm}$.

Head. Face whitish yellow, somewhat wider $(1.3 \times)$ than frontal ocellus. Eye with inner 5-6 ommatidia distinctly brilliantly greenish blue on frontal face (about $1 / 3$ of inner frontal eye) (MSSC). Uppermost 5 postocular bristles brown, lower 5 pale yellow. Palp ovoid rectangular, large, more than $1 / 3$ of eye, pale reddish yellow. Antenna with scape and pedicel mainly yellow, scape distinctly, and pedicel very slightly infuscated dorsally; first flagellomere pale brown, triangular with rather acute apex, 1.4× as long as deep and $1.5 \times$ as long as scape and pedicel combined. Arista $1.4 \times$ as long as first 3 antennal joints, subapical, with microscopic pubescence.

Thorax. Mesonotum remarkably flattened on dorsum; including lower pleura, scutellum and postnotum pale reddish yellow and strongly contrasting with pale brown upper pleura. Metapleura with upper $1 / 2$ brown and lower $1 / 2$ pale reddish yellow. $7 \mathrm{ac}$, about as long as distance between rows. 5 dc. One small sutural bristle present, with $2^{\text {nd }}$ equal-sized bristle on the left side of the mesonotum. Abdomen with tergites pale brown, brown from $3^{\text {rd }}$ tergite onwards. Sternites whitish yellow, $5^{\text {th }}$ strongly reduced to enclose hypopygium; with dark pubescence. Genital capsule large, about $2 \times$ as long as 5 th tergite, globular, brownish black. Hypopygium (Fig. 5) with hypandrium whitish yellow, with smooth apex; phallus largely brown with subapical dorsal bend; surstylus with black apical hook, and simple midventral bristle; VPE and DPE evident; postgonites with strong hook-like apical processes; cercus transparant, very long, reaching posterior margin of $3^{\text {rd }}$ sternite, elongate, tapering; with strongest bristles on basal $1 / 2$ dorsally.

Wing. Halter slightly infuscated, especially on shaft. Wing pale, with veins $\mathrm{R}_{4+5}$ an $\mathrm{M}_{1+2}$ diverging towards wing apex. Proximal section of vein $\mathrm{M}_{1+2} 0.9 \times$ as long as apical section; proximal section of vein $\mathrm{CuA}_{1} 2.5 \times$ as long as apical section; $\mathrm{CuA}_{\mathrm{x}}$ ratio 1.6.

Legs including coxae and trochanters whitish yellow, with tibia I and II and $5^{\text {th }}$ tarsomeres of legs I-III darker. Femur I with 1 erect ventral bristle inserted at basal $1 / 4$, $0.7 \times$ as long as femur is deep (MSSC), basad of row of small inclined av bristles; with 1 small av and $1 \mathrm{pv}$ preapical bristles. Femur II with 1 row of robust, erect, black pv bristles along whole length, less than $1 / 2$ as long as femur is deep, and with apical ones more inclined towards apex; with 1 ad, 1 av and 1 large pv preapical bristles. Femur III with 1 row of robust, erect, black pv bristles on middle $1 / 2,1 / 3$ as long as femur is deep; with 1 strong av preapical bristle; ad preapical bristle absent. Tibia I brown on entire dorsal face and on less than apical $1 / 4$ on ventral face, otherwise whitish yellow; slightly thickened, especially at middle, with dense dorsal and pv 
pubescence, without dorsal bristles. Tibia II brownish yellow with 3 ad (inserted at basal $1 / 4,1 / 2$ and $2 / 3$ ) and $1 \mathrm{pd}$ bristles in left leg, and 2 ad and 1 pd bristles in right leg. Tibia III with 3 small ad and 3 pd bristles, and 6 minute erect ventral setae amid dense pubescence. First tarsomere of leg I brownish, with strong ventral bristles, as long as tarsal depth. First tarsomere of leg III $0.7 \times$ as long as $2^{\text {nd }}$ tarsomere.

Female. Body length 2.7-3.0 mm; wing length 2.3-2.5 $\mathrm{mm}(\mathrm{n}=3)$. Similar as in male, except for the following: face wider, $1.7 \times$ as wide as frontal ocellus. Eye uniformously red. Palp large, about $2 / 5$ of eye, ovoid, pale brown with reddish yellow basis. Antenna with yellow scape and pedicel, former hardly infuscated dorsally; $1^{\text {st }}$ flagellomere brownish yellow, raddish-shaped, $1.2 \times$ as long as wide and $1.2 \times$ as long as scape and pedicel combined. Arista $1.7 \times$ as long as first three antennal joints, apical, inserted on outer face. Wing $3.1 \times$ as long as wide. Proximal section of vein $\mathrm{M}_{1+2}$ as long as apical section; proximal section of vein $\mathrm{CuA}_{1} 2.8 \times$ as long as apical section; $\mathrm{CuA}_{\mathrm{x}}$ ratio 1.6. Abdomen with $1^{\text {st }}$ tergite yellowish with dark posterior rim, $2^{\text {nd }}$ till $6^{\text {th }}$ tergite pale brown; sternites whitish yellow as in male; 8th abdominal segment conical, reddish brown, with 8 reddish brown dornen and pale brown cerci. Legs including coxae mainly pale yellow, with femur II distinctly infuscated on ventral face. Trochanters slightly infuscated, brownish. Femur I without basoventral bristle. Tibia I brownish yellow, gradually darker towards apex. Tibia II with 2 ad and 1 pd bristle. Tibia III with 4 minute erect ventral setae amid dense pubescence in basal $1 / 2$. Tarsi pale yellow, with $1^{\text {st }}$ and $5^{\text {th }}$ tarsomere of leg I slightly darker.

Type material. Holotype, ô, CANADA, Ontario, R.M. of Durham, Town of Georgina, Jacksons Point, Sibbald Point Provincial Park (grassy path at clearing in wooded marshland at Georgian Bay, site II), 29.vi.2001, MSW, M. Pollet (to be deposited in CNC; W). Paratypes, CANADA: Prince Edward Island (PEI), Northumberland Strait Shore, Tyron, saltmarsh (trap \# 1B), 1 \% ; saltmarsh (trap \# 1C), 1 \% , 3.viii.1993, ET, D. Giberson (all LEMQ; W); USA: Maine, [Casco Bay, $2 \mathrm{~km} \mathrm{~W}$ of Small Point Beach] Hermit Island, 19, 10.vii.1986, J. Cumming (CNC; D).

Etymology. The name "longicercus" refers to the elongate, tapering cercus in this species.

\section{GENUS AUSTRALACHALCUS POLLET, 2005}

Type species: Achalcus albipalpus Parent, 1931

Australachalcus albipalpus (Parent, 1931) designated by Pollet (2005)

The following generic character states were decisive to place the following species in Australachalcus: 6 dc. Six pubescent abdominal segments in both sexes. Hypandrium with ventral apex clearly spined. Epandrial setae inserted at basis of epandrial lobe.

\section{Australachalcus latipennis sp.n. (Figs 7-11)}

Diagnosis. Small, rather stout, dark species with yellow bristles and pubescence. Antenna mainly dark brown with pedicel paler ventrally; scape with dorsal pubescence. Arista distinctly shorter than first three antennal joints,

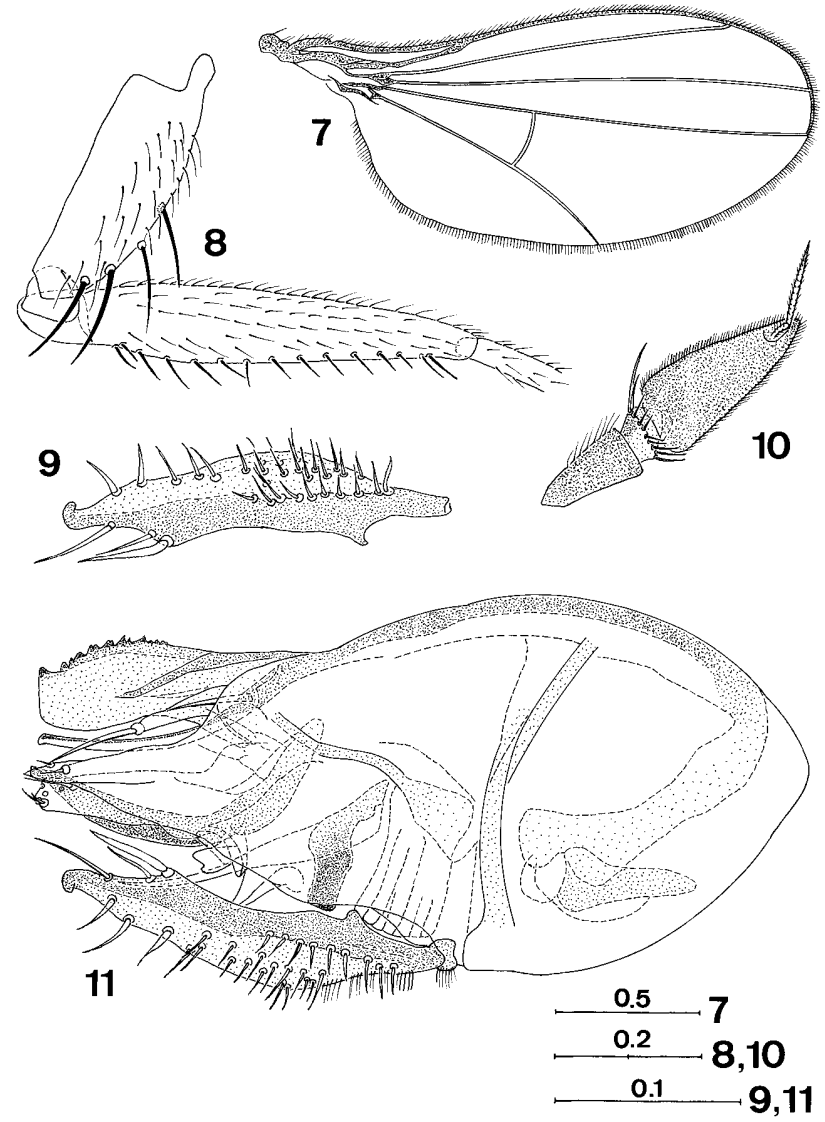

Figs 7-11. Australachalcus latipennis sp.n. (holotype). 7 wing; 8 - coxa and femur I; 9 - (right) cercus; 10 - antenna; 11 - hypopygium.

yellowish white in female. All postocular bristles yellow. Wing broad in male, about $2 \times$ as long as wide. Femur I without basoventral bristle. Femur III without distinct ad preapical bristle. Tibia I without dorsal bristle. Tibia III with 2 ad and 2 pd bristles. Hypandrium with spined ventral apex and cerci strongly sclerotized, with apical hook directed laterally.

Description. Male. Rather stout species with yellow bristles and pubescence. Body length $2.0 \mathrm{~mm}$; wing length $1.8 \mathrm{~mm}$.

Head. Face brown, rather wide, about as wide as (large) frontal ocellus. Frons dark brown, very wide. Occiput dark brown, shining. All postocular bristles pale yellow. Palp subcircular, small, $1 / 5$ of eye, yellowish white; with pale pubescence, and pale apical bristle. Antenna (Fig. 10) mainly dark with brown scape and pedicel mainly yellowish white, darker on dorsal $1 / 2$; scape with yellow dorsal pubescence; $1^{\text {st }}$ flagellomere brown, elongate triangular, about $2.3 \times$ as long as deep and $1.5 \times$ as long as scape and pedicel combined. Arista $0.3 \times$ as long as first three antennal joints, subapical, with microscopic pubescence.

Thorax. Mesonotum and scutellum dark brown, pleura slightly paler. Postnotum brown with distinct black frontolateral triangle. Metapleura mainly whitish yellow, only dark on dorsal $1 / 5.7$ ac, less than $2 \times$ as long as distance between rows. One very strong sutural bristle present, 
only slightly smaller than dc. About 10 strong, pale, additional bristles present between first $3 \mathrm{dc}$, presutural and sutural bristles. Upper pleura with 1 minute seta, lower pleura with 3 minute setae and 1 pale prothoracic bristle. Abdomen with tergites brown, paler laterally. Sternites brownish with whitish central area, latter largest on $2^{\text {nd }}$ and $3^{\text {rd }}$ sternites. Genital capsule pale brown. Hypopygium (Fig. 11) with apicoventrally spined hypandrium; phallus very slender and straight; surstylus rather compact with all bristles inserted near apex; VPE and DPE present; postgonites short, with apical $1 / 2$ dark; cercus (Fig. 9) strongly sclerotized, moderately sized, elongate, with apical hook directed laterally.

Wing (Fig. 7). Halter large, pale; squama pale. Wing broad, $2 \times$ as long as wide, pale, with pale veins; with $\mathrm{R}_{4+5}$ and $\mathrm{M}_{1+2}$ diverging at wing centre, parallel in apical $1 / 4$, $\mathrm{M}_{1+2}$ showing slight sinuous bend. Proximal section of $\mathrm{M}_{1+2} 0.7 \times$ as long as apical section; proximal section of vein $\mathrm{CuA}_{1} 1.4 \times$ as long as apical section; $\mathrm{CuA}_{\mathrm{x}}$ ratio 1.8.

Legs, including coxae and trochanters, whitish yellow; with pale pubescence and bristles, including external bristle on coxa III and preapical bristles on femur II and III. Femur I (Fig. 8) without erect ventral bristle (small erect pv seta on right leg), with 1 row of strong inclined av bristles along whole length, bristles at basis $0.5 \times$ as long as deep; with 1 moderately sized pv preapical bristle. Femur II with 1 strong ad, 1 indistinct av and 1 strong pv preapical bristles. Femur III with 1 strong av preapical bristle; distinct ad and pv preapical bristles absent, although 2 ad setae near apex slightly larger than others. Tibia I without dorsal bristles. Tibia II with 2 ad bristles at less than basal $1 / 4$ and less than basal $3 / 5$, and 1 pd bristle. Tibia III with 2 small ad and 2 small pd bristles and with dense ventral pubescence without erect setae. Tarsus I-III entirely whitish yellow, only tarsus III slightly darker than tibia III. First tarsomere of leg III $0.8 \times$ as long as $2^{\text {nd }}$ tarsomere.

Female. Body length $2.2 \mathrm{~mm}$; wing length $2.1 \mathrm{~mm}$. As in male, except for the following: face dark brown, yellowish white on clypeus, broad, about $2.5 \times$ as wide as (large) frontal ocellus. Palp large, about $1 / 3$ of eye. Antenna brown with scape paler on ventral apex and pedicel paler on inner face; $1^{\text {st }}$ flagellomere brown, ovoid triangular, $1.5 \times$ as long as deep and as long as scape and pedicel combined. Arista yellowish white, $0.7 \times$ as long as first three antennal joints, inserted apically on outer face, with microscopic pubescence. Metapleura entirely whitish yellow. Wing $2.5 \times$ as long as wide. Proximal section of $\mathrm{M}_{1+2} 0.6 \times$ as long as apical section; proximal section of vein $\mathrm{CuA}_{1} 1.3 \times$ as long as apical section; $\mathrm{CuA}_{\mathrm{x}}$ ratio 2.1 . Abdominal tergites pale brown, shining; $2^{\text {nd }}$ till $5^{\text {th }}$ sternites yellowish white with central brown spot, $6^{\text {th }}$ entirely pale brown; 8th abdominal segment with strong bristles instead of dornen, and dark brown, slender cerci. Femur I without distinct av bristles. Femur II with 1 row of short inclined ventral bristles on basal $1 / 2$, less than $1 / 2$ as long as femur is deep (only on right leg). Femur III with preapical ad bristle rather indistinct, yellow, at middle of anterior face. Tarsi pale yellow. Pubescence on legs brownish.

Type material. Holotype, $\hat{0}$, USA, Arizona, Cochise Co., Huachuca Mts., 5354 Ash Cyn., R2, 0.5 mi W. Hwy 92 (5100 ft), 22.-31.x.1992, MT, N. McFarland (CNC; W). Paratype, same site as holotype, 1\%, 1.-11.xi.1992, MT, N. McFarland $(\mathrm{CNC} ; \mathrm{W})$

Etymology. The name "latipennis" refers to the distinctly broad wing in this species.

Remarks. Meunier (1907a) described Achalcus latipennis from baltic amber. It remains, however, unclear on what basis this species was assigned to Achalcus as apart from the "almond-shaped" first flagellomere with the apical arista, not a single other character seems to be typical achalcine. In fact, the pedicel is cup-shaped without a strong apical crown of bristles and veins $\mathrm{R}_{4+5}$ and $\mathrm{M}_{1+2}$ are parallel (Meunier, 1907b, 1908). In addition, H. Ulrich (ZFMK) studied the holotype (no. Z 4600) at GMUG in 2001 and took the following notes (translated from his original notes and adapted to terminology used here): "Small species with small, oblique hypopygium. Antenna with large ovoid $1^{\text {st }}$ flagellomere corresponding with fig. 20 in Meunier (1907b). Legs stout, femora II and III without (distinct) preapical ad bristles. Veins $\mathrm{R}_{4+5}$ and $\mathrm{M}_{1+2}$ parallel; veins $\mathrm{R}_{2+3}$ and $\mathrm{R}_{4+5}$ parallel in more than apical $1 / 2$ and cell $R_{3}$ wider only at wing apex due to caudad bend of $R_{4+5}$ which remained parallel with $\mathrm{M}_{1+2}$. $\mathrm{CuA}_{\mathrm{x}}$ ratio about 1.5." Moreover, he discovered that the holotype was a male, in contrast to the diagnosis by Meunier (1907b). These supplementary data confirm that A. latipennis does not belong to Australachalcus nor Achalcus

\section{Other specimens}

Six Achalcus female specimens could not be assigned with certainty to any of the seven described nor the five unnamed species (sp. 'NA01'-'NA02', sp. 'NA04''NA06', see Pollet \& Cumming, 1998) and are briefly characterized below. Comparison with all described Neotropical and Palaearctic species revealed no conspecificity with any of these species either.

Achalcus sp. 'NA07', 1 \%, USA, Montana, Phillips Co., Landusky, Montana Gulch Campground, Little Rocky Mountains, $4000 \mathrm{ft}$ [in damp area with Equisetum sp., along small shaded stream], 14.vii.2001, J.B. Runyon (MTEC; D): pale species with face and frons whitish, heavily dusted. Palp pale yellow with black pubescence and bristles. Both antennae lacking. Thorax pale reddish yellow, darker anteriorly, between ac and on prescutellar depression. $5 \mathrm{dc}$, ac nearly reaching $4^{\text {th }} \mathrm{dc}$. Sutural bristle absent. Proximal section of vein $\mathrm{M}_{1+2} 0.8 \times$ as long as apical section. Proximal section of $\mathrm{CuA}_{1} 2.3 \times$ as long as apical section; $\mathrm{CuA}_{\mathrm{x}}$ ratio 1.8. Abdomen entirely yellowish white, with 6 pubescent segments. Legs including coxae and tarsi whitish yellow, with brown spot on coxa II, $5^{\text {th }}$ tarsomeres of all legs brown, and entire tarsus III darker than tibia III. Femur II with 1 ad preapical bristle, and femur III with 1 strong ad and 1 strong ventral preapical bristle. Tibia I with 2 dorsal bristles. Tibia II with 2 strong ad and 1 strong pd bristles. Tibia III with 
2-3 strong ad and 3 strong pd bristles. Body length 2.1 $\mathrm{mm}$, wing length $2.2 \mathrm{~mm}$.

Achalcus sp. 'NA08', 1 \%, USA, California, Humboldt Co., Little River (grassy edge of river), 14.vii.1990, SW, R. Hurley (MTEC; D): dark species with reddish brown face and dark brown, dusted frons. Palp ovoid, dark brown, with black pubescence and bristles. Antenna with scape and pedicel brownish yellow; $1^{\text {st }}$ flagellomere ovoid triangular, dark brown with basoventral $1 / 2$ brownish yellow. Arista nearly $2 \times$ as long as first three antennal joints. Thorax including pleura, and abdomen entirely dark brown, with black pubescence and bristles. $5 \mathrm{dc}$, ac nearly reaching $4^{\text {th }} \mathrm{dc}$. One sutural bristle. Proximal section of vein $\mathrm{M}_{1+2} 0.8 \times$ as long as apical section. Proximal section of $\mathrm{CuA}_{1} 2.3 \times$ as long as apical section; $\mathrm{Cu} \mathrm{A}_{\mathrm{x}}$ ratio 1.6. Legs mainly pale yellow, with tibia and tarsus I brownish yellow, and tarsus III dark yellow; coxa I whitish yellow, infuscated only on extreme basis anteriorly, coxa II with brown spot, and coxa III brownish yellow. Femur I and III with 1 av and pv row of rather strong bristles, inclined towards apex. Femur II with 1 ad preapical bristle, and femur III with 1 strong ad and 1 strong ventral preapical bristle. Tibia I with 1 dorsal bristle. Tibia II with 2 ad and 1 pd bristles. Tibia III with 3 strong ad and 3 strong pd bristles. Body length $2.2 \mathrm{~mm}$, wing length $2.4 \mathrm{~mm}$.

Achalcus sp. 'NA09', 2 으, same site as Achalcus sp. 'NA08', 16.vii.1990, SW, R. Hurley (MTEC; D): similar to sp. 'NA08', but: thorax paler, brown, with yellowish humeri, upper pleura and scutellar margins. Abdominal tergites dark brown, sternites brownish to whitish yellow. Proximal section of vein $\mathrm{M}_{1+2} 0.8 \times$ as long as apical section. Proximal section of $\mathrm{CuA}_{1} 2.3 \times$ as long as apical section; $\mathrm{CuA}_{\mathrm{x}}$ ratio 1.5. Legs pale yellow with tibia I brownish yellow, gradually darker on apical $1 / 2$. Tarsi I, II and III darker, with $5^{\text {th }}$ tarsomeres brown. Body length 1.9-2.2 mm, wing length $2.1-2.5 \mathrm{~mm}$.

Achalcus sp. 'NA10', 1 \%, USA, California, Marin Co., Inverness, 10.v.1968, D.D. Munroe (CNC; D): antenna with scape and pedicel entirely reddish yellow; $1^{\text {st }}$ flagellomere elongate triangular, $1.5 \times$ as long as wide, dark brown with basoventral $1 / 3$ reddish yellow. Palp large, $1 / 3$ of eye, whitish yellow with large dark brown spot on apical $1 / 2$. Thorax reddish yellow with lateral dark brown spot on anterior part (in front of $1^{\text {st }} \mathrm{dc}$, humeral and presutural bristle), and brown prescutellar depression. Pleura pale brown. Abdomen with brown tergites and sternites; sternites of $2^{\text {nd }}$ abdominal segment paler. One sutural bristle. Halter pale. Proximal section of vein $\mathrm{M}_{1+2} 0.9 \times$ as long as apical section. Proximal section of $\mathrm{CuA}_{1} 2.3 \times$ as long as apical section; $\mathrm{CuA}_{\mathrm{x}}$ ratio 1.8. Legs pale yellow with tibia I and tarsi I, II and III brownish yellow; tarsus I dark brown from apical $1 / 2$ of $2^{\text {nd }}$ tarsomere onwards; tarsus II dark brown from apical $1 / 2$ of $3^{\text {rd }}$ tarsomere onwards; $5^{\text {th }}$ tarsomere of leg III dark brown. Normal chaetotaxy of legs. Wing with $\mathrm{CuA}_{1}$ strong, brown. Wing length $2.5 \mathrm{~mm}$ (abdomen partly eaten by Dermestidae).

Achalcus sp. 'NA11', 1오, CANADA, Manitoba, 2 mi. NE Treesbank, along Souris River, 49 $40^{\prime} \mathrm{N} 99^{\circ} 36^{\prime} \mathrm{W}$, 11.viii.1993, MT, R. Gallaway (CNC; D): antenna with scape and pedicel entirely whitish yellow; $1^{\text {st }}$ flagellomere dark brown with basal $1 / 4$ whitish. Palp yellowish white. Thorax including pleura pale reddish yellow. Abdominal tergites yellowish white with narrow transversal brown band on anterior part of tergites; sternites whitish. Sutural bristle absent. Halter pale. Proximal section of vein $\mathrm{M}_{1+2}$ as long as apical section. Proximal section of $\mathrm{CuA}_{1} 2.2 \times$ as long as apical section; $\mathrm{CuA}_{\mathrm{x}}$ ratio 1.8. Legs whitish yellow with tibia I slightly darker. Femur II with 1 ad preapical bristle, and femur III with 1 strong ad and 1 strong ventral preapical bristles. Tibia III with 2 strong ad and 3 strong pd bristles. Body length $2.3 \mathrm{~mm}$, wing length $2.0 \mathrm{~mm}$.

\section{DISCUSSION}

All but one of the known Nearctic Achalcus species belong to the A. flavicollis species group. The lack of dorsal bristles on tibia I and the absence of a preapical ad bristle on femur III are considered sufficient to exclude $A$. longicercus from this group at present. The distinctly dorsoventrally flattened thorax in both sexes seems to be a unique feature of this species as well, but this might be considered an autapomorphy. The male of this species differs further from its Nearctic and Palaearctic congeners by the brilliantly greenish blue inner frontal ommatidia, the pv row of robust erect bristles on femur II and III and strong hook-like apical processes of the postgonites. Although a preapical ad bristle on femur III is absent in the European $A$. vaillanti as well, in the latter species it only applies to the male and thus must be regarded as a MSSC.

The number of dorsal bristles on tibia I seems to be of significant diagnostic and presumably also phylogenetic relevance. Like A. longicercus, all Australachalcus species, all species of the Achalcus costaricensis Pollet, 2005 species group, and Achalcus brevicornis Pollet, 2005 (Chile) lack dorsal bristles bristles on tibia I (see Pollet, 2005). One dorsal bristle is shared by all 16 species of the A. flavicollis species group, Achalcus niger Pollet, 2005 (Chile) and six unnamed Nearctic Achalcus species currently represented by females only. Moreover, the latter six species all feature a dark brown thorax, brown to dark brown abdominal tergites and a mainly dark antenna. Apart from the Chilean Achalcus micromorphoides Pollet, 2005, the presence of two dorsal bristles on tibia I is a character state only encountered in A. bicolor, $A$. dytei, A. similis and four unnamed Achalcus species.

Australachalcus latipennis does not fit any of the four South and Central American Australachalcus lineages as defined in Pollet (2005) nor the Palaearctic A. melanotrichus species group (Pollet \& Stark, in press). Indeed, it lacks the terminal flag of the midventral bristle of the surstylus present in three Neotropical species groups, the Palaearctic $A$. melanotrichus species group, and the unplaced Neotropical $A$. acornis Pollet, 2005 and $A$. browni Pollet, 2005. Further on, it also lacks the following characters typical for each Neotropical species group: basoventral bristle of femur $\mathrm{I}$, and $\mathrm{CuA}_{\mathrm{x}}$ ratio $\leq 1$ (A. albipalpus species group Pollet, 2005); strong basal 


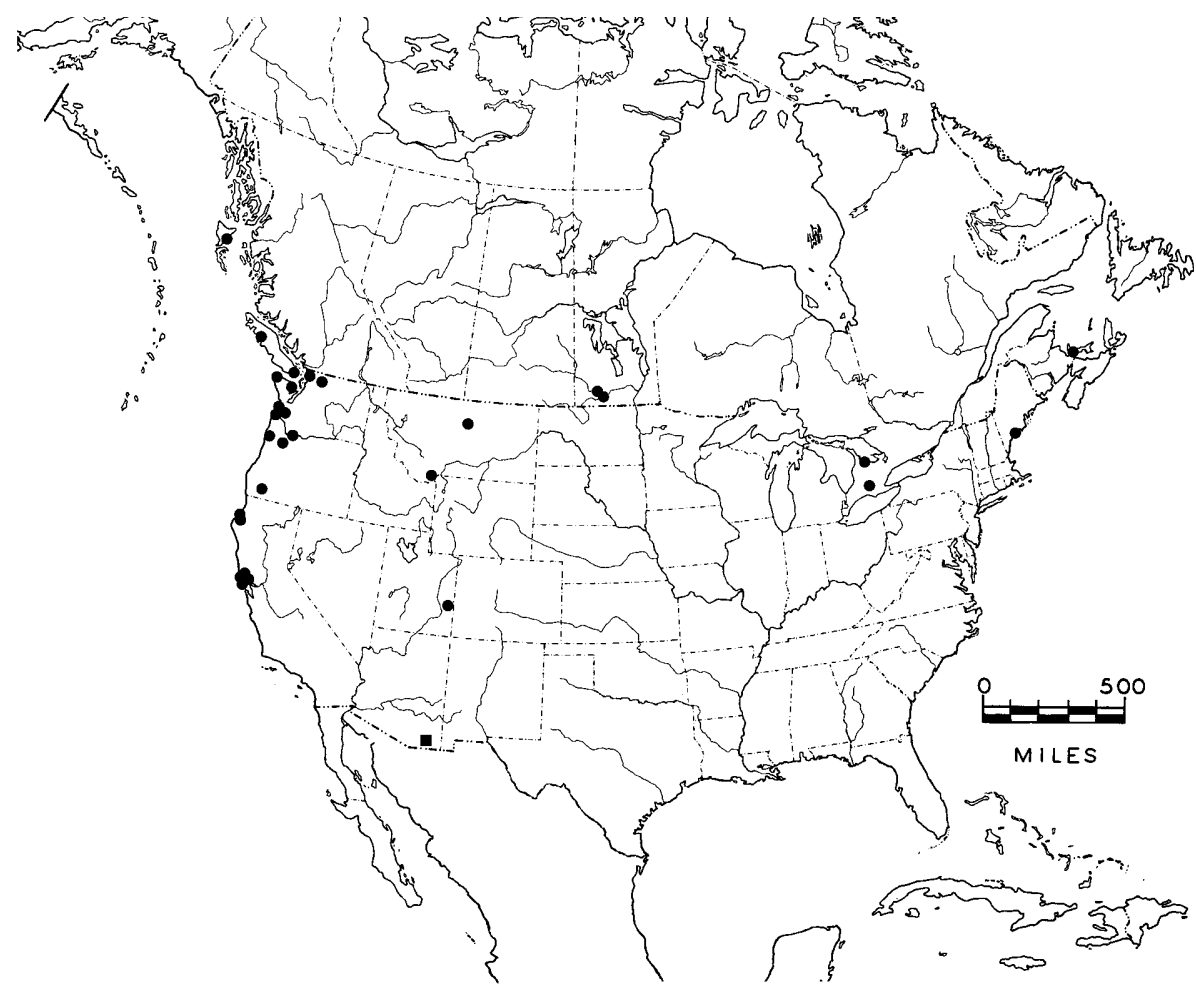

Fig. 12. Distribution of Achalcinae in America north of Mexico.

- Achalcus sp.

- Australachalcus latipennis.

av and/or pv bristles of femur II, and robust epandrial lobe with large, flattened apical bristle (A. cummingi species group Pollet, 2005); basoventral bristle of femur I, strong basal av and/or pv bristles of femur II, and dorsal recurrent apical process of aedeagus (A. robustus species group Pollet, 2005). A. latipennis shares the simple or reduced surstylus of the $A$. edwardsae species group Pollet, 2005, but lacks the white, dense, short pubescence of coxa I, and the small, triangular cercus with strong apical bristles as present in $A$. edwardsae (Van Duzee, 1930) and $A$. incisicornis Pollet, 2005. The discovery of

TABLE 1. Geographical origin by states and provinces of specimens of Nearctic Achalcus studied. Specimens listed as males/females. Abbreviations of states and provinces: BC: British Columbia; CA: California; MB: Manitoba; ME: Maine; MT: Montana; ON: Ontario; OR: Oregon; PEI: Prince Edward Island; UT: Utah; WA: Washington.

\begin{tabular}{|c|c|c|c|c|c|c|c|c|c|c|c|}
\hline \multirow{2}{*}{ Species } & \multicolumn{4}{|c|}{ Pacific coast of North America } & \multicolumn{6}{|c|}{ Remaining central and eastern states/provinces } & \multirow{2}{*}{ No specimens } \\
\hline & $\mathrm{BC}$ & WA & OR & $\mathrm{CA}$ & MT & UT & MB & $\mathrm{ON}$ & ME & PEI & \\
\hline Achalcus californicus & - & - & - & $1 /-$ & - & - & - & - & - & - & 1 \\
\hline Achalcus dytei & $1 / 1$ & $6 / 30$ & $-/ 1$ & - & - & - & - & - & - & - & 39 \\
\hline Achalcus oregonensis & - & - & $1 /-$ & - & - & - & - & - & - & - & 1 \\
\hline Achalcus similis & - & $4 / 6$ & $2 /$ & - & - & - & - & - & - & - & 12 \\
\hline Achalcus sp. NA01 & - & $-/ 1$ & - & - & - & - & - & - & - & - & 1 \\
\hline Achalcus sp. NA02 & - & $-/ 1$ & - & - & - & - & - & - & - & - & 1 \\
\hline Achalcus sp. NA04 & - & - & - & $-/ 3$ & - & - & - & - & - & - & 3 \\
\hline Achalcus sp. NA05 & $-/ 1$ & - & - & - & - & - & - & - & - & - & 1 \\
\hline Achalcus sp. NA06 & - & - & - & $-/ 1$ & - & - & - & - & - & - & 1 \\
\hline Achalcus sp. NA08 & - & - & - & $-/ 1$ & - & - & - & - & - & - & 1 \\
\hline Achalcus sp. NA09 & - & - & - & $-/ 2$ & - & - & - & - & - & - & 2 \\
\hline Achalcus sp. NA10 & - & - & - & $-/ 1$ & - & - & - & - & - & - & 1 \\
\hline Achalcus bicolor & - & - & - & - & $2 /-$ & - & $2 / 6$ & $-/ 1$ & - & - & 11 \\
\hline Achalcus longicercus & - & - & - & - & - & - & - & $1 /-$ & $-/ 1$ & $-/ 2$ & 4 \\
\hline Achalcus utahensis & - & - & - & - & - & $2 /-$ & - & - & - & - & 2 \\
\hline Achalcus sp. NA07 & - & - & - & - & $-/ 1$ & - & - & - & - & - & 1 \\
\hline Achalcus sp. NA11 & - & - & - & - & - & - & $-/ 1$ & - & - & - & 1 \\
\hline No. of specimens & $1 / 2$ & $10 / 38$ & $3 / 1$ & $1 / 8$ & $2 / 1$ & $2 /$ & $2 / 7$ & $1 / 1$ & $-/ 1$ & $-/ 2$ & 83 \\
\hline No. of species & 2 & 4 & 3 & 6 & 2 & 1 & 2 & 2 & 1 & 1 & 17 \\
\hline
\end{tabular}


more Nearctic Australachalcus species might help to clarify its phylogenetic position.

At present, no Achalcus species from Mexico have been examined. The two new Achalcus species described here and the five additional unnamed species represent a considerable extension of the distribution range of this genus in North America, especially in the centre (Manitoba, Montana) and the east (Ontario, Maine, PEI) (Fig. 12). Only four species have been recorded from more than one state or province (Table 1). A. bicolor seems to have a rather wide distribution, whereas the other three species are restricted to the east (A. longicercus) or west (A. dytei, A. similis). At present, the west coast shows the highest species richness although this might be explained by more intensive collecting efforts in this region. Australachalcus latipennis from Arizona is the northernmost record of this genus in the New World, with the nearest congeneric species being $A$. browni Pollet from Costa Rica (Pollet, 2005). Apart from these two species, thus far representatives of this genus have only been recorded from Chile (Pollet, 2005), New Zealand (Parent, 1933, as Achalcus), Europe (Pollet, 1996, as Achalcus) and Japan (Pollet \& Stark, in press).

The observation by Pollet \& Cumming (1998) that most Nearctic Achalcus species are hygrophilous and favour coastal regions or riparian habitats along rivers is confirmed by the new records. Eight specimens of $A$. bicolor were collected along the Assiniboine - Souris river complex, and the two Montana specimens of this species were trapped in a pasture during a study on grazing effects (Hurley, pers. comm.). On the other hand, A. longicercus definitely seems to prefer coastal habitats, including saltmarshes, along the Atlantic Ocean (PEI, Maine) and wooded habitats (Ontario) at the Georgian Bay. The latter species was collected with emergence traps on PEI, which indicates that the immature stages are tolerant of saltmarsh conditions. In Ontario, a single male of $A$. longicercus was collected by net sweeping among numerous Dolichopus and Gymnopternus specimens.

In the northern part of the Nearctic (from Oregon, Washington and Montana east to Maine and entire Canada), Achalcus species were collected during June till September, particularly during July - August with 29 and 27 specimens resp. of six species in each month. This phenology pattern corresponds roughly with the seasonal activity of most European species. Next to A. utahensis (August) and specimens of three unnamed Achalcus species (July) with a comparable phenology, three Californian species were trapped in May and the two specimens of $A$. latipennis even during late autumn (22 October -11 November). It is possible that species of this genus that generally can be termed cool-preferent, adapted their activity period in the dry southwest to avoid the unfavourable summer conditions. However, it is clear that much more information is needed to provide hard evidence for this and other assumptions.

ACKNOWLEDGEMENTS. I am most grateful to J. Cumming (CNC) and other members of the CanaColl committee for a grant to study the CNC-collections in July 2001 and thus enabled me to extract two of the new species. Many thanks are further due to J. Cumming, S. Brooks (CNC), R. Hurley (MTEC) and J. Runyon (Dept of Entomology, Pennsylvania State University, University Park, Pennsylvania, USA), who kindly provided me with additional Nearctic Achalcus material. I am especially indebted to S. Brooks with whom I searched for productive dolichopodid sites in southern Quebec and Ontario in July 2001. S. Brooks, J. Cumming and D. Bickel (Australian Museum, Sydney, Australia) helped me deciding on the key to females, H. Ulrich (ZMFK) kindly allowed me to use his personal notes on Achalcus latipennis and R. Hurley (Montana State University, Bozeman, USA) delivered the blank map. Finally, the highly constructive and relevant comments by referee P. (C.E.) Dyte (Datchet, UK) largely improved an earlier draft of the manuscript. This paper is a contribution of the Research Group Terrestrial Ecology of the Ghent University (Ghent, Belgium) and the Department of Entomology of the KBIN (Brussels, Belgium).

\section{REFERENCES}

Bickel D.J. 1994: The Australian Sciapodinae (Diptera: Dolichopodidae), with a Review of the Oriental and the Australasian Faunas, and a World Conspectus of the Subfamily. Rec. Aus. Mus. (Suppl. 21): 1-394.

Cumming J.M., Sinclair B.J. \& Wood D.M. 1995: Homology and phylogenetic implications of male genitalia in Diptera Eremoneura. Entomol. Scand. 26: 120-151.

HaRmston F.C. \& Miller L.S. 1966: New and little known Dolichopodidae from the Pacific Northwest and intermountain areas. Proc. Entomol. Soc. Wash. 68(2): 88-93.

Meunier F. 1907a: Monographie des Dolichopodidae de l'ambre de la Baltique [part]. Naturaliste (2) 29: 209-211.

MeUnier F. 1907b: Monographie des Dolichopodidae de 1'ambre de la Baltique [part]. Naturaliste (2) 29: 245-246.

MeUnIER F. 1908: Monographie des Dolichopodidae de l'ambre de la Baltique [part]. Naturaliste (2) 30: 29-30.

Parent O. 1933: Etude monographique sur les Diptères Dolichopodides de Nouvelle-Zélande. Ann. Soc. Sci. Bruxelles (B) 53: 325-441.

Pollet M. 1992: Impact of environmental variables on the occurrence of dolichopodid flies in marshland habitats in Belgium (Diptera: Dolichopodidae). J. Nat. Hist. 26: 621-636.

Pollet M. 1996: Systematic revision and phylogeny of the Palaearctic species of the genus Achalcus Loew (Diptera: Dolichopodidae) with the description of four new species. System. Entomol. 21: 353-386.

Pollet M. 2000: A documented Red List of the dolichopodid flies (Diptera: Dolichopodidae) of Flanders. Communications of the Institute of Nature Conservation 8. Brussels, $190 \mathrm{pp}$. [in Dutch, English abstr.].

Pollet M. 2005: Systematic revision of Neotropical Achalcus and a related new genus (Diptera: Dolichopodidae, Achalcinae) with comments on their phylogeny, ecology and zoogeography. Zool. J. Linn. Soc. 143: 27-73.

Pollet M., Brooks S.E. \& Cumming J.M. 2004: Catalog of the Dolichopodidae (Diptera) of America north of Mexico. Bull. Am. Mus. Nat. Hist. 283: 1-114.

Pollet M. \& Cumming J.M. 1998: Systematic revision of Nearctic species of Achalcus Loew (Diptera: Dolichopodidae) with comments on their phylogeny, ecology and zoogeography. System. Entomol. 23: 371-385.

POLLET M. \& STARK A. in press: Australachalcus japonicus sp.n., the first record of an achalcine species from Japan (Diptera: Dolichopodidae, Achalcinae). Bull. Inst. R. Sci. Nat. Belg. (Entomol.) 00: 000-000.

RoBinson H. 1970: 40. Family Dolichopodidae. In Papavero N. (ed.): A Catalogue of the Diptera of the Americas South of the United States. Universidade de São Paulo, Museu de Zoologia, São Paulo, pp. 1-92.

Received June 17, 2004; revised and accepted December 15, 2004 